\title{
Sudden Death- Case series of Ruptured Esophageal Varices
}

Ishita Thakur, Rashid Nehal Khan, Abhijit Rudra

Forensic Medicine and Toxicology, Armed Forces Medical College, Pune

*Corresponding author: Ishita Thakur, Forensic Medicine and Toxicology, AFMC, Pune, India, Tel: 7263077907; E-mail: atihsi532@gmail.com

Received date: June 15, 2018; Accepted date: September 19, 2018; Published date: September 26, 2018

Copyright: (C) 2018 Thakur I, et al. This is an open-access article distributed under the terms of the Creative Commons Attribution License, which permits unrestricted use, distribution, and reproduction in any medium, provided the original author and source are credited.

\author{
Abstract \\ Introduction \\ Sudden death due to Gastroinstestinal $(\mathrm{Gl})$ causes amount to $10 \%$ of all sudden death. Esophageal varices is one \\ of the GI causes of sudden death. It develops as a complication of liver cirrhosis. The prevalence of esohgaeal \\ varices in cirrhosis patients is $50 \%$ and mortality rate varies between $20 \%-35 \%$ with male female ratio of $1: 9$. The \\ one year bleeding rate of small and large varices is $5 \%$ and $15 \%$. Mortality rate increases with increased age.
}

\section{Case-Series}

Six case of sudden death were seen in the mortuary of a tertiary hospital. The six cases were males, alcoholics. On autopsy, similar findings of cirrhotic liver and hemorrhagic mucosa of the stomach with bleeding spots on lower one third of esophagus were observed.

\section{Discussion}

Collaterals develop with development of portal hypertension. Some sites are pre disposed to rupture like the esophageal varices. Risk factors of variceal rupture are red streaks in lumen of esophagus and deranged liver function tests. On gross examination, signs of deranged liver functions are noted. On internal examination, esophagus is everted attached to the stomach and varices are seen shine to through the mucosa. Liver had cirrhotic changes and spleen was enlarged and congested in all the six cases.

\section{Conclusion}

The case series emphasizes the importance of fatal esophageal variceal hemorrhage as an important cause of sudden death occurring outside the hospital in alcohol-addicted individuals, often in isolated scenarios.

Keywords: Esophageal varices; Cirrhosis; Liver

\section{Introduction}

World Health Organization (WHO) defines sudden death in its International classification of diseases, version 10 (ICD-10) as death, non-violent and not otherwise explained, occurring in less than twenty four hours from the onset of symptoms [1].

$10 \%$ of sudden deaths are due to gastrointestinal causes [2]. Esophageal varices is one of its cause. They are Porto-systemic collaterals - i.e., vascular channels which link the portal venous and the systemic venous circulation. It is a complication of cirrhosis. It develops in sub mucosa of the distal esophagus. It is a life-threatening complication of portal hypertension. The mortality rate is $10 \%-30 \%$ of all upper gastrointestinal bleeding [3]. The hemodynamic abnormality manifests as bleeding varices or ruptured varices in one third of the patients [4].

Spontaneous stoppage of bleeding occurs in up to $40 \%$ of individuals [5,6] .Mortality with the first variceal bleeding is 30\%-50\% $[7,8]$. Highest number of deaths have been reported in winter than summer [9].

\section{Case Series}

Case 1:
A 47 year old male, known alcoholic brought to hospital in unresponsive state where he was declared dead. On postmortem examination: faint post mortem lividity noted. On Examination of abdominal cavity, stomach contained $700 \mathrm{~mL}$ of blood. Lower end of esophagus shows thickened wall with mucus and streaks of blood. Liver had cirrhotic changes (yellowish colored with macronodules, fibrosed in appearance) and weighed $1100 \mathrm{~g}$. On dissection, cut section were pale and architecture was poor. Spleen was enlarged, brain and lungs were congested and oedematous. No other external/internal injuries were present on the body.

\section{Case 2:}

A 44 year old male, known alcoholic with sudden onset of hematemesis after which he fell unconscious and was taken to the hospital where he was declared dead. On examination, stomach contained $1000 \mathrm{~mL}$ of blood in stomach Lower end of esophagus shows thickened wall with mucus and streaks of blood. Liver showed cirrhotic changes (yellowish colored with macronodules and micronodules, fibrosed in appearance) weighing. On dissection, cut section were pale. Spleen was enlarged, brain and lungs were congested and oedematous and kidneys were pale. No other external/internal injuries were present on the body.

\section{Case 3:}

A 35 year old male, known alcoholic with history of being found unresponsive at home. The individual was unemployed and used to 
stay alone at home. On examination, yellowish discoloration of the sclera, poor oral hygiene with dried blood stains at the nostrils. On examination, Stomach was cut along the greater curvature and it showed $800 \mathrm{~mL}$ of blood with congested mucosa (Figures 1 and 2). Lower end of esophagus shows multiple streaks of blood and tortuous blood vessels. Liver weighed $1200 \mathrm{~g}$, on its gross examination multiple nodules were present over the surface of the liver, yellow tan colour. On dissection of liver, pale cut sections with distorted architecture were seen. Spleen was enlarged, brain and lungs were congested and oedematous. No other external/internal injuries were present on the body.

\section{Case 4:}

A 41 year old male, known alcoholic with sudden onset of heamtemesis after which individual fell unconscious and was declared dead. On examination eyes had yellowish discoloration of the sclera. Stomach was cut along the greater curvature and it showed $1000 \mathrm{~mL}$ of blood with congested mucosa (Figure 3) Lower end of esophagus shows thickened wall with mucus and streaks of blood. Liver weighed $1100 \mathrm{~g}$, grossly multiple nodules were present over the surface of the liver, yellow tan colour (Figure 6). On dissection of liver, pale cut sections. Spleen was enlarged, brain and lungs were congested a oedematous and kidneys were pale. No other external /internal injuries were present on the body.Liver was sent for Histopathological examination (Figure 10).

\section{Case 5:}

60 year old man known alcoholic and diabetic with complaints of hematemesis, weakness, abdominal pain since two months turning unresponsive and declared dead. Individual was admitted earlier for abdominal pain. Post mortem lividity not appreciated with obese built and nourishment. Lower end of esophagus showed multiple bleeding points and tortuous blood vesssles (Figure 4). Stomach contained $100 \mathrm{~mL}$ of blood. Liver pale, with multiple macro- and micro-nodules of varying size (Figure 5) and was sent for histopathology examination (Figure 7). Spleen. Kidneys were congested.

\section{Case 6:}

42 year old man chronic alcoholic with complaints of hematemesis and weakness since two months.individual was admitted for weakness a month back and was given multivitamins. Post mortem lividity appreciated with average built and nourishment. Lower end of esophagus shows multiple bleeding points and tortuous blood vessels. Peritoneal cavity contains $2 \mathrm{~L}$ of yellow colored clear fluid. Stomach contained $200 \mathrm{~mL}$ of blood, mucosa rugae are hemorrhagic and prominent. Liver pale, with multiple nodules of varying size and was sent for histopathological examination (Figure 8). Enlarged spleen.

\section{Methodology}

Present studys was conducted from the year 2014-2016 and we had six cases with similar findings. In our study the age of the sample ranged from 35 years to 60 years. All the cases were that of male, with history of alcohol intake and deranged liver function. Mallory-Weiss syndrome was ruled out on gross examination. Esophagus is left attached to the stomach. Stomach was opened along the greater curvature of the stomach. A string is tied at the upper end of the unopened esophagus and then pulled through the lumen to evert the esophagus. Varices shine through the mucosa.

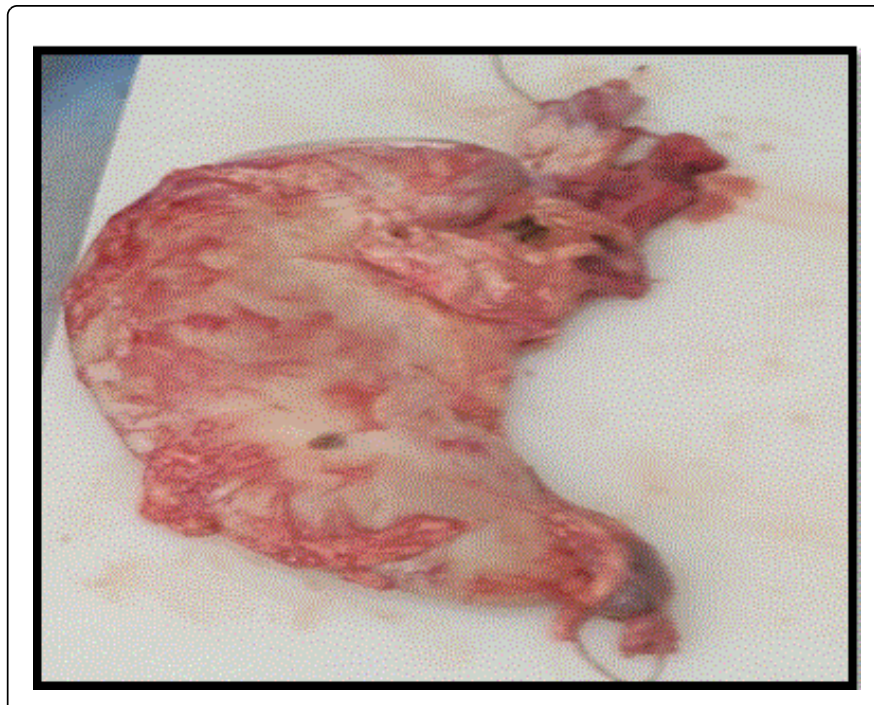

Figure 1: Stomach: Gross Examination; Gross examination of the stomach removed for examination. Greater curvature measures 29 $\mathrm{cm}$ and lesser curvature $11 \mathrm{~cm}$. A string is tied at the upper end of unopened esophagus and lower end of stomach.

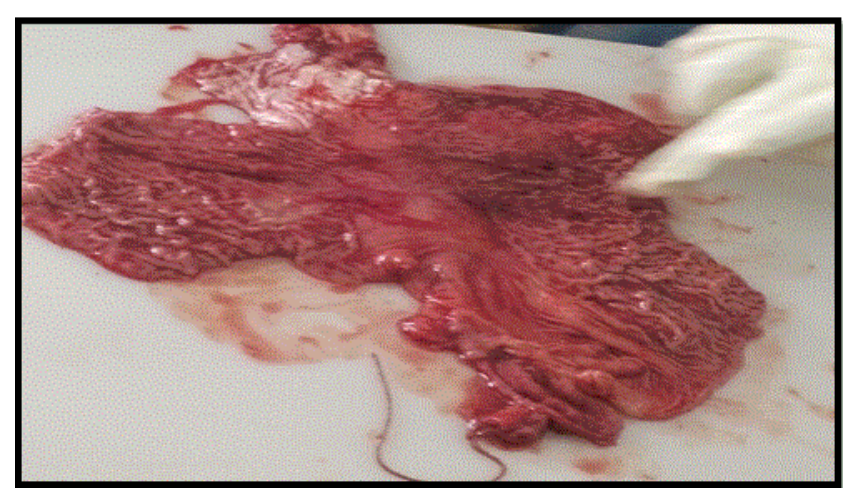

Figure 2: Stomach: Cut Section with the esophagus left attached to the stomach, it is opened along the greater curvature. Cut section of the stomach shows a circular area in lesser curvature with loss of rugosity and measure $8 \mathrm{~cm} \times 7 \mathrm{~cm}$ almost reaching the pyloric region.

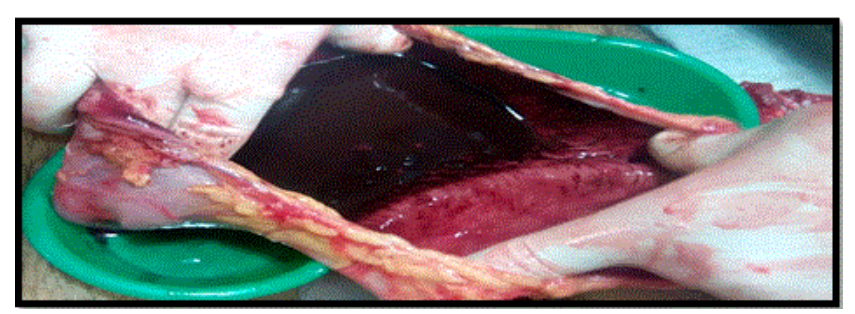

Figure 3: Cut section of Stomach; Stomach is cut along its greater curvature and cut section of stomach shows stomach with blood. 
Citation: Thakur I, Khan RN, Rudra A (2018) Sudden Death- Case series of Ruptured Esophageal Varices. J Forensic Med 3: 124. doi:

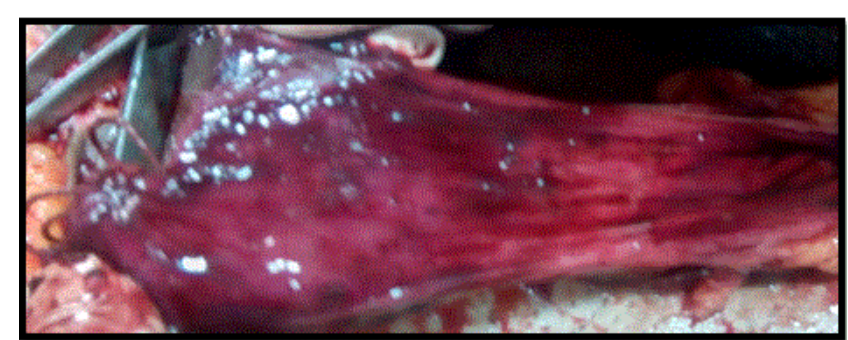

Figure 4: Everted lumen of Esophagus; String is tied to the upper end of unopened esophagus and is then pulled through the lumen to evert the esophagus. Varices are seen to shine through the mucosa with multiple bleeding spots.

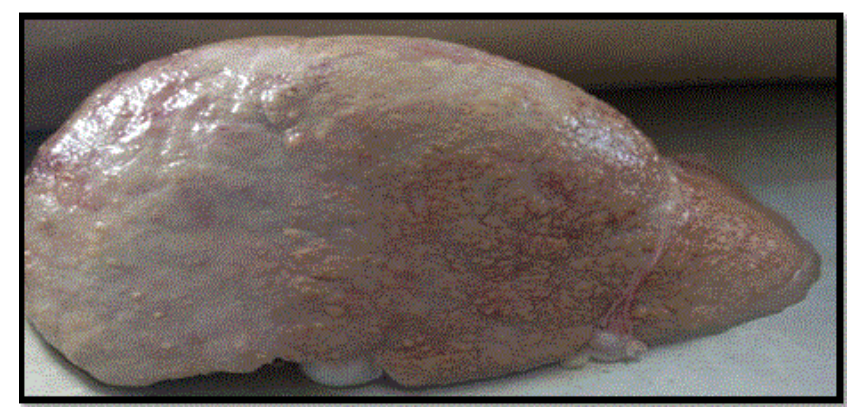

Figure 5: Liver on gross examination; Gross examination of the liver showing macro and micro nodules of varying size over the surface of the liver.

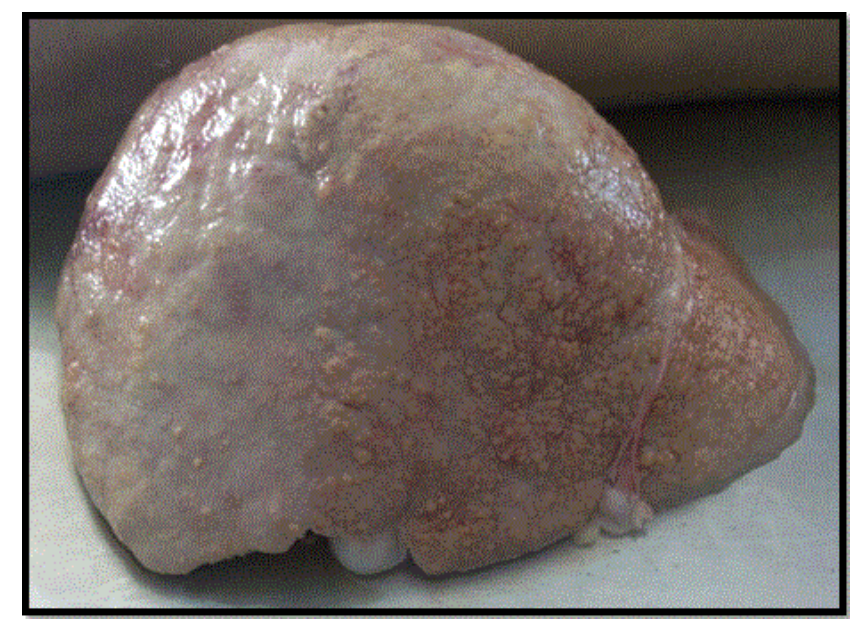

Figure 6: Liver on gross examination; Gross of the liver showing yellow tan colour with multiple nodules spread throughout the surface of the liver.

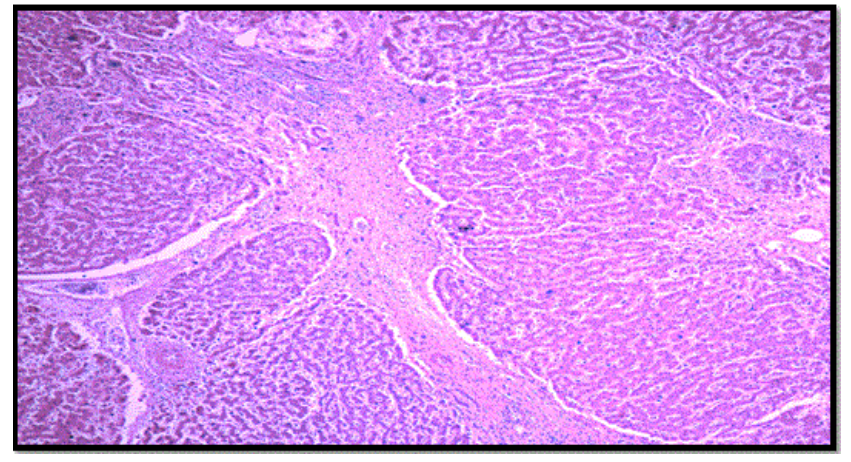

Figure 7: Histopathology of Liver; Histopathology of liver showing perivenular and pericellular fibrosis (chicken-wire fence pattern) Central-central and/or central-portal fibrous septa Micronodular cirrhosis is seen in the histopathological examination of the liver.

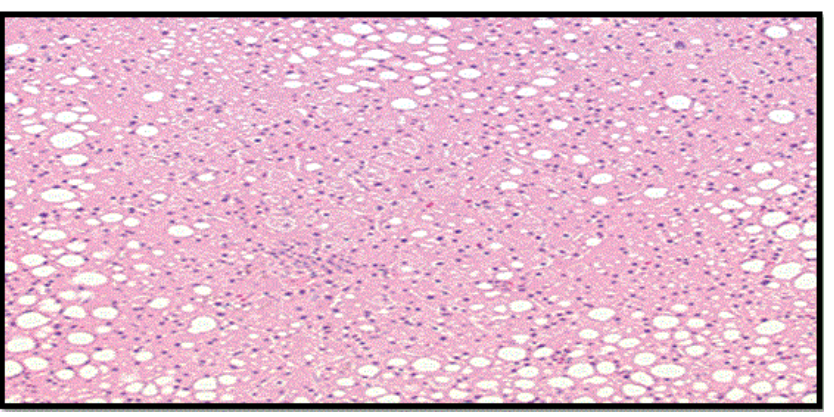

Figure 8: Histopathology of Liver; Sections from the liver both right and left lobes show regenerating parenchymal nodules seperated by dense bands of fibrosis. The liver cell plate thickness is more than 3 cell layer thick. Mild periportal inflammation comprising of lymphocytes and plasma cells. Hepatocytes show evidence of macrovesicular steatosis.

\section{Results}

In present study, age range of cases were 35 years- 60 years. All the cases were of male sex (100\%), known alcoholic and belonged to lower socio-economic strata. In all the cases there was history of vomiting of blood and turning unconscious. Co-morbidities like diabetes and anemia were present in a two cases. Post mortem lividity was not appreciated in three of our cases and was faint in two and in one was appreciated. Four out of six cases had poor built and one was obese and one was average. Icterus was noted in the sclera of two individuals. Enlarged spleen was seen in five out of six cases. In all the six cases, stomach contained blood. It varied within a range of $100 \mathrm{ml}-1500 \mathrm{ml}$. Ascites was noted in three out of six individuals in the case series. In our study none of the six cases had any previous medical records. In four out of six cases distended and ruptured varices were seen in the lower third of the esophagus and in two cases the mucosa was hemorrhagic, congested and with streaks of blood (Table 1). 


\begin{tabular}{|l|l|}
\hline Clinical Feature & Trait \\
\hline Age range & $35-60$ years \\
\hline Sex & Male \\
\hline Nourishment & Poor \\
\hline History & Alcohol, Hematemesis \\
\hline Co-morbidities & Diabetes \\
\hline Employement & Unemployed (03) \\
\hline
\end{tabular}

Table 1: Results describing clinical features.

\section{Discussion}

\section{Portosystemic collaterals}

Collaterals are a known complication of liver cirrhosis and portal hypertension and serve as a link between portal venous and systemic circulation [10]. Complications of varices are bleeding and rupture [2]. The prevalence of esophageal varices in cirrhosis patients is $50 \%$ and bleeding from the varices lead to a mortality of $20 \%-35 \%$ [11].

\section{Applied Anatomy and Physiology}

The portal blood flow is approximately 1 liter per minute, the mean pressure is about $7 \mathrm{~mm} \mathrm{Hg}$, and $70 \%$ of the hepatic oxygen is supplied by the portal vein $[12,13]$.

In portal hypertension there is a rise in portal pressure and a collateral circulation develops. In cirrhosis with a severe intrahepatic block to portal venous flow, one tenth of the blood flow reaches the hepatic veins, and the rest through collaterals which decreases portal pressure [12,14].

Abnormal microcirculation leads to occult gastrointestinal bleeding in such cases [15].

The veins within the epithelium form "Cherry red spots" under condition of portal hypertension appreciated on endoscopy and this predicts the risk of hemorrhage [16].

Truncal zone, perforating zone, palisade zone and gastric zone are the venous system in gatsroesophageal region. The water shed between the portal and systemic system is the palisade zone. Turbulent flow in the veins of the perforating zone with thinning of the muscularis mucosa lead to rupture of varices $[12,17,18]$. Recurrence occurs due to the enlargement of superficial venous plexus 16 and angiogenesis [17].

Intramucosal vascular abnormalities (ecstatic capillaries and venules, microthrombi) in stomach of patients and portal hypertension also called portal hypertensive gastropathy $[19,20]$ and watermelon stomach [21].

Increased resistance is due to architectural distortion of the liver parenchyma, systemic vasodilation and salt and water retention [22] .

\section{Lapace's law}

Increased wall tension leads to variceal rupture.

Wall tension $=($ Variceal pressure - Luminal pressure $) \times$ Radius $/$ Thickening of variceal wall.
Variceal wall opposes distension which leads to build up of wall tension. Rupture occurs when the wall tension reaches the critical point of the elastic limit [23].

\section{Cause of esophageal varices}

Alcohol is the leading cause of esophageal varices in the west. Hepatitis B is the leading cause of esophageal varices in India [13].

\section{Age}

In our study we had cases in the age range of 35 years- 60 years. Mean age in studies by WGO is 50.7 years 2, Weinberg et al found the varices in older age group 24, in Tsokos et al. was 50.6 years 25 . Hansson et al. [24] and Nochimowski et al. [25] found varices in children. Risk of rupture increases with age 14.

\section{Sex}

In our study, $100 \%$ of the cases were male. Tsokos et al., LaBrecque et al., Weinberg et al. $[2,26,27]$ had maximum cases in males.

\section{Socio economic strata}

In our study $100 \%$ of the cases belonged to low socio-economic strata. This was consistent with LaBreque et al., Weinberger et al. $[2,26]$.

\section{Alcoholic}

All six cases were alcoholic. The findings were similar to studies by and Tsokos et al. [27], Klebner et al. [28-31].

\section{Nourishment}

Four out of six cases had poor built and one was obese and one was average. Alcohol is said to have empty calories. The alcoholic drinks are enriched with vitamins and minerals but not as much as the requirement of the body [32].

\section{Icterus}

Icterus was noted in the sclera of two individuals. Icterus is the most immediate symptom in liver disease due to excess bilirubin in plasma $[13,16]$.

\section{Enlarged spleen}

In our study enlarged spleen was seen in five out of six cases. Observations vary from normal $[30,33,34]$ to congested spleen 33 to enlarged spleen $[31,32,35]$.

\section{Stomach and blood}

In all the six cases stomach contained blood. It varied within a range of $100 \mathrm{ml}-1500 \mathrm{ml}$. The findings in other studies ranged from blood stained mucosa $[26,30,31,34,35]$ to frank blood $[26,34]$.

\section{Ascites}

Ascites was observed in $50 \%$ of our cases. As no previous medical records were available, it was diffilcut to comment on the nature of the fluid as time had elapsed since death. Serum ascites albumin gradient 
was found to be associated with splenomegaly and gastroinstestinal bleeding [32,36] and a High SAAG indicates portal hypertension [37].

\section{Esophagael ruptured varices}

In $67 \%$ of cases distended and ruptured varices were seen in the lower third of the esophagus and in remaining 33\%, the mucosa was thickened and with streaks of blood. Similar findings mentioned in textbooks [38,39,13] and Tsokos et al. [26] .Weinberg et al. [24] observed that varices are difficult to identify histologically. Varices in the upper part of the esophagus usually seen in old age, superior vena cava obstruction or congestive heart failure [37,38].

\section{Methods of demonstration}

We kept the esophagus attached with the stomach, opened the stomach along the greater curvature. String is tied to the upper end of unopened esophagus and then pulled throught the lumen to evert the esophagus. Varices shine through the mucosa [40].

Varices can be accentuated by formalin fixation. If esophagus is not everted the varices can be injected with barium sulphate gealtin and roentgenographs can be prepared [40]. Varices can also be demonstrated by separating the layers of the esophagus and drying it over an absorbent paper. Histological examination and radiography documentation of the varices have also been done [41].

\section{Conclusion}

- Undiagnosed cases of liver cirrhosis are commonly seen in stages of portal hypertension. The cases we came across were brought to hospital after vomiting and turning unconscious.

- In sudden unexpected death, role of Forensic pathologists is vital and need for medicolegal autopsy in such cases due to sudden death demands more attention to the underlying pathology

- Esophageal varices is the most important complication of portal hypertension.

- Ruptured esophageal varices are located in the lower third of the esophagus or in the esophago-gastric junction.

- Varices are found more frequently in males.

- Alcohol abuse increases the risk of variceal bleeding. Blood clotting is altered.

- Rupture of varices is a cause of sudden death in asymptomatic or previously undiagnosed patients.

- In the present study, bloodstains at the death scene and unusual body positions of the deceased that aroused suspicion of a violent death were leading reasons for conducting a medicolegal autopsy.

- Apart from aspects of forensic pathology, the demographics of our study population are also noteworthy from the viewpoint of social medicine.

- The data we present stress the importance of fatal esophageal variceal hemorrhage as a relevant cause of sudden death occurring outside the hospital in socially isolated, alcohol-addicted individuals.

\section{References}

1. International classification of diseases (ICD-10) (2005). Geneva, World Health Organization.

2. LaBrecque D, Khan A, Sarin S, Le Mair A, Dite P (2014) Esophageal varices. World Gastroenterol Organ Glob Guidel 1:4.
3. Tsao GG, Sanyal AJ, Grace ND, Carey W (2007) Prevention and management of gastroesophageal varices and variceal hemorrhage in cirrhosis. J Hepatol 46: 922-938.

4. Bosch J, Berzigotti A, Garcia-Pagan JC, Abraldes JG (2008) The management of portal hypertension: Rational basis, available treatments and future options. J Hepatol 1: 68-92.

5. D’Amico G., R. De Franchis ( 2003) Upper digestive bleeding in cirrhosis. Post-therapeutic outcome and prognostic indicators. J Hepatol 38: 599-612.

6. Carbonell N, Pauwels A, Serfaty L, Fourdan O, Levy VG, et al. (2004) Improved survival after variceal bleeding in patients with cirrhosis over the past two decades. J Hepatol 40: 652-659.

7. Khuroo MS, Khuroo NS, Farahat KL, Khuroo YS, Sofi AA, et al. (2005) Metaanalysis: Endoscopic variceal ligation for primary prophylaxis of oesophageal variceal bleeding. Aliment Pharmacol Ther 21:347-361.

8. Chalasani N, Kahi C, Francois F, Pinto A, Marathe A, et al. (2003) Improved patient survival after acute variceal bleeding: A multicenter, cohort study. Am J Gastroenterol 98: 653-659.

9. Katz A, Biron A, Ovsyshcher E, Porath A (2000) Seasonal variation in sudden death in the Negev desert region of Israel. Isr Med Assoc J 2: 17-21.

10. Garcia-T (2001) Current management of the complications of cirrhosis and portal hypertension: Variceal hemorrhage, ascites, and spontaneous bacterial peritonitis. Gastroenterology 120: 726-748.

11. Jensen DM (2002) Endoscopic screening for varices in cirrhosis: Findings, implications, and outcomes. Gastroenterology 122: 1620-1630.

12. Stadlbauer VP, Wright GA, Banaji M, Mukhopadhya A, Mookerjee R, et al. (2008) Relationship between activation of the sympathetic nervous system and renal blood flow autoregulation in cirrhosis. Gastroenterology 134: 111-119.

13. Dan LL, Fauci AS, Kaspe DL, Hauser SL, Loscalzo J, et al. (2012) Harrison's principles of internal medicine. $18^{\text {th }}$ edition, McGraw-Hill Companies.

14. John D, Peter D, Howdle Y (2002) Anatomy of the normal liver. In: Comprehensive Clinical Hepatology. $1^{\text {st }}$ edition, Bortmann: Harcourd Publisher Limited. Pp: 1-18.

15. Machiedo GW, Zaets SB, Berezina TL, Xu DZ, Feketova E, et al. (2009) Trauma-hemorrhagic shock-induced red blood cell damage leads to decreased microcirculatory blood flow. Crit Care Med 37: 1000-1010.

16. Sherlock S, Dooley J (2002) The portal venous system and portal hypertention. In: Disease of the Liver and Biliary System. Oxford London Edinburgh Mebourne: Blackwell. Pp: 147-186.

17. Paquet KJ (2000) Causes and pathomechanisms of oesophageal varices development. Med Sci Monit 6: 915-928.

18. Ahidjo A, Tahir A (2015) A handbook of introductory abdominal ultrasound for West Africa.

19. Merli M, Nicolini G, Angeloni S, Gentili F, Attili AF, et al. (2004) The natural history of portal hypertensive gastropathy in patients with liver cirrhosis and mild portal hypertension. Am J Gastroenterol 99:1959.

20. Patwardhan VR, Cardenas A (2014) The management of portal hypertensive gastropathy and gastric antral vascular ectasia in cirrhosis. Aliment Pharmacol Ther 40: 354-362.

21. Wells CD, Harrison ME, Gurudu SR, Crowell MD, Byrne TJ, et al. (2008) Treatment of gastric antral vascular ectasia (watermelon stomach) with endoscopic band ligation. Gastrointest Endos. 68: 231-236.

22. Sanyal AJ, Bosch J, Blei A, and Arroyo V ( 2008) Portal hypertension and its complications. Gastroenterology 134: 1715-1728.

23. Schmidt-NK (1990) Animal physiology: Adaptation and environment, Cambridge University Press, Cambridge.

24. Hansson CJ. Varices of the oesophagus in children. Acta radiol 25: 507-513.

25. Nochimowski J (1932) About fatal bleeding from esophageal varices in traps without cirrhosis. Ztschr f Path 43: 463-475.

26. Weinberg $\mathrm{T}$ (1949) Observations on the occurrence of varices of the esophagus in routine autopsy material. Am J Clin Pathol 19: 554-557. 
Citation: Thakur I, Khan RN, Rudra A (2018) Sudden Death- Case series of Ruptured Esophageal Varices. J Forensic Med 3: 124. doi: 10.4172/2472-1026.1000124

Page 6 of 6

27. Tsokos M, Türk EE (2002) Esophageal variceal hemorrhage presenting as sudden death in outpatients: A study of 45 medicolegal autopsy cases. Arch Pathol Lab Med 126: 1197-200.

28. Kleber G, Sauerbruch T, Ansari H, Paumgartner G (1991) Prediction of variceal hemorrhage in cirrhosis: A prospective follow-up study. Gastroenterology 100: 1332-1337.

29. Lieber CS (2000) Alcohol: Its metabolism and interaction with nutrients. Annu Rev Nutr 2: 395-430.

30. Liangpunsakul S, Ulmer BJ, Chalasani N (2003) Predictors and implications of severe hypersplenism in patients with cirrhosis. Am J Med Sci 326: 111-116.

31. Takuma Y, Nouso K, Morimoto Y, Tomokuni J, Sahara A, et al. (2013) Measurement of spleen stiffness by acoustic radiation force impulse imaging identifies cirrhotic patients with esophageal varices. Gastroenterology 144: 92-101.

32. Hoefs JC (1983) Serum protein concentration and portal pressure determine the ascites fluid protein concentration in patients with chronic liver disease. J Lab Clin Med 102.

33. Okuda K, Kono K, Ohnishi K, Kimura K, Omata M, et al. (1984) Clinical study of eighty-six cases of idiopathic portal hypertension and comparison with cirrhosis wit splenomegaly. Gastroenterology 86: $600-610$.
34. Shah SH, Hayes PC, Allan PL, Nicoll J, Finlayson ND (1996) Measurement of spleen size and its relation to hypersplenism and portal hemodynamics in portal hypertension due to hepatic cirrhosis. Am J Gastroenterol 91: 2580-2583.

35. Chalasani N, Imperiale TF, Ismail A, Sood G, Carey M, et al. (1999) Predictors of large esophageal varices in patients with cirrhosis. Am J Gastroenterol 94: 3285-3291.

36. Garcia-Tsao G, Groszmann RJ, Fisher RL, Conn HO, Atterbury CE et al. (1985) Portal pressure, presence of gastroesophageal varices and variceal bleeding. Hepatology 5:419-424.

37. Kahsner JT (1942) Human pathology. $6^{\text {th }}$ edition, Philadelphia: J. B. Lippincott Company. Pp: 563.

38. Boyd W (1944) Pathology of internal diseases. $4^{\text {th }}$ edition, Philadelphia: Lea and Febiger. Pp: 322.

39. Christian HA(1942) Osier's principles and practice of medicine. $14^{\text {th }}$ editon, New york: Appleton-century Co. Inc. Pp: 38.

40. Ludwig J (2002) Handbook of autopsy practice. Springer Science \& Business Media.

41. Abramowsky CR, Gonzalvo AA (1975) Postmortem demonstration of esophageal varices by a simple method. Am J Clin Pathol 64: 672-677. 